\title{
Effective Degradation of Humic Acids in Water by Zero Fenton Process
}

\author{
Santos, N.O. ${ }^{1}$, Spadotto, J.C. ${ }^{1}$, Solórzano, I.G. ${ }^{1}$, Campos, L.C. ${ }^{2}$, Teixeira, L.A.C ${ }^{1,3}$ \\ 1. Department of Chemical and Materials Engineering, PUC-Rio, Rio de Janeiro, Brazil \\ 2. Department of Civil, Environmental and Geomatic Engineering, UCL, London, UK \\ 3. Peróxidos do Brasil Ltda (Solvay Group)
}

Fractions of natural organic matter such as humic acids (HA) can lead to the formation of toxic compounds such as trihalomethane compounds (THMs) after reaction with chlorine. These by-products can cause problems in drinking water treatment plants [1]. The aim of this study is to evaluate the Fenton Zero oxidative process in the degradation of HA. This process leads to the generation of hydroxyl radicals ( $\mathrm{OH}$ ) from the reaction Zero Valent Iron (ZVI) / hydrogen peroxide $\left(\mathrm{H}_{2} \mathrm{O}_{2}\right) /$ iron (II) [2]. The main advantages of this process are the reduction of operational costs caused by the type of chemical compounds used and the no need for special equipment.

In this work, ZVI has been tested in the metallic form of iron wire cuts $\left(50 \mathrm{~g} . \mathrm{L}^{-1}\right)$. Besides to the as-received condition, the iron wire cuts were subjected to two pre-treatments (i) heat treatment $\left(950^{\circ} \mathrm{C}\right.$ for 30 minutes followed by water quenched) and ii) chemical treatment (pickling of $\mathrm{HCl}-5 \%$ ). The experiments have been performed using HA solution at $\mathrm{pH} 4.5$ in jar test $(200 \mathrm{rpm})$. To verify the degradation of HA, samples have been monitored at $254 \mathrm{~nm}$ with a spectrophotometer (Shimadzu UV 1800). In order to verify the oxidation and the microstructure of the ZVI, light optical microscope (Zeiss Axioplan 2) and scanning electron microscopy (SEMJEOL JSM-7100F)) coupled with X-ray energy dispersive spectroscopy (XEDS) detect or have been used.

The SEM image shown in Figure 1a presents the ZVI surface in the as-received condition (untreated). It's observed that the surface in this condition does not show oxidation. After the reaction (Figure 1b) the formation of small oxidation sites (indicated by arrows) have been verified and these have been confirmed by EDS spectra (Figure 1e). Meanwhile, when the ZVI was chemically treated the reaction led to increased oxidation on the material surface, as shown in Figure 1c. However, when the ZVI pre-treated followed by water quenched and pickling was applied in the reaction, a significant increase in the oxidation area on the surface was observed (Figure 1d). Figure 1f presents the HA degradation during the Zero Fenton process. As shown in this figure, HA degradation achieved within 60 minutes of reaction $91.5 \%$ and $100 \%$ using untreated ZVI (blue line) and ZVI after pickling (green line), respectively. However, Zero Fenton process using ZVI submitted to heat treatment followed by water quenched and pickling showed $100 \%$ of HA degradation within 30 minutes of reaction (red line). Results indicate that the degradation of HA using iron wire cuts after heat treatment followed by water quenched and pickling was slightly faster when compared to the process using ZVI pre-treated by pickling. This difference in the degradation rate is probably due to the microstructural transformation of the iron wire cuts. In the as-received condition (Figure 2a) the microstructure is constituted of ferrite (white) and perlite (dark). On the other hand, the iron wire cuts post-heat treatment presents a martensitic microstructure (Figure 2b). Such drastic cooling introduces high surface tensile residual stresses, which are probably responsible for the higher oxidation observed in the surface of the material $[3,4]$.

\section{References:}

[1] Richardson, S.D. et al, Rev. Mutat. Res 636 (1-3) (2007), p. 178.

[2] Bremner, D.H. et al, Applied Catalysis B: Environmental 63(1-2) (2006), p. 15.

[3] ASM Handbook, vol. 1, ASM International, 1990.

[4] The authors are grateful to Peróxidos do Brasil Ltda (Solvay Group), to CBPF for the acess to the LabNano Electron Microscopy facilities and to the Brazilian Funding Agency- CNPq. 


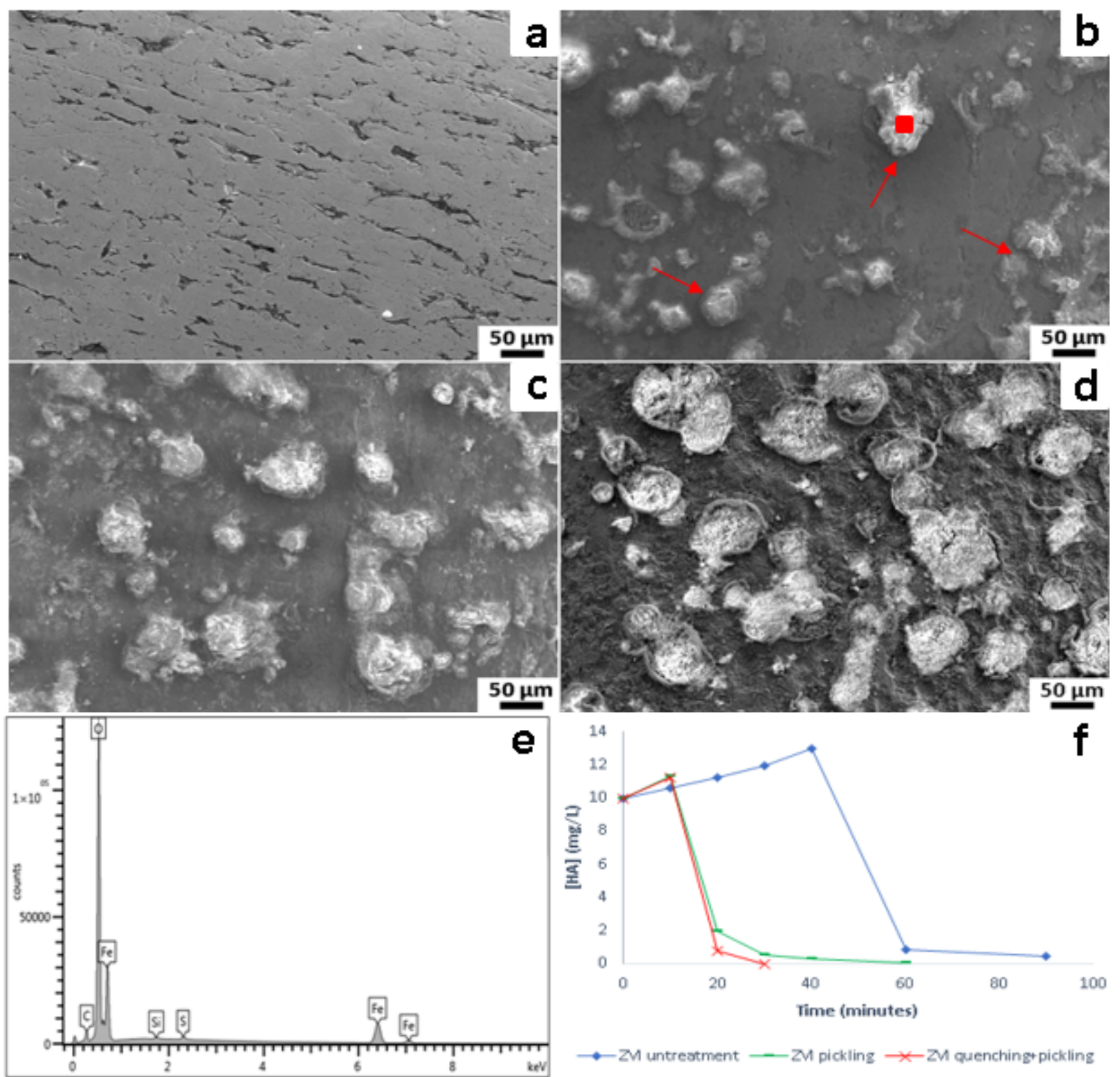

Figure 1. SEM images of iron cut. (a) in the as-received condition; (b) in the as-received condition post-reaction Zero Fenton; (c) in the after pickling condition; (d) in the post-heat treatment condition after pickling; (e) EDX spectra obtained from the region indicated by red square in (b); (f) HA degradation by Zero Fenton Process in the different treatment conditions.
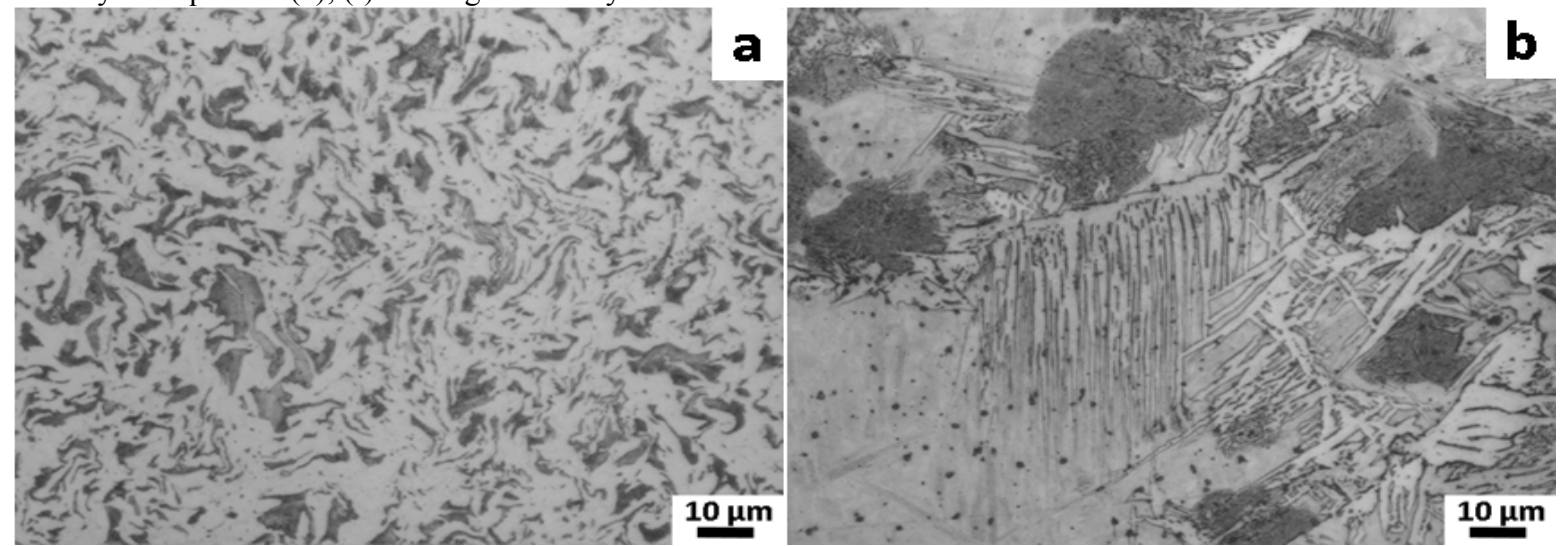

Figure 2. Light optical micrographs of iron cuts microstructure (a) in the as-received condition and (b) in the post-heat treatment at $950{ }^{\circ} \mathrm{C}$ for 30 minutes followed by water quenched. 